Леонід Михайлович Артюшин (доктор техн. наук, професор) ${ }^{1}$

Микола Вікторович Бугайов (канд. техн. наук, науковий співробітник) ${ }^{2}$

${ }^{1}$ Держсавний науково-дослідний інститут авіації, Київ, Украӥна

2итомирський військовий інститут імені С. П. Корольова, Житомир, Украӥна

\title{
АЛГОРИТМ ВИЯВЛЕННЯ АКУСТИЧНИХ СИГНАЛІВ БЕЗПІЛОТНИХ ЛІТАЛЬНИХ АПАРАТІВ НА ОСНОВІ АНАЛІЗУ ФРАКТАЛЬНОЇ PO3MIPHOCTI
}

У роботі проведено аналіз статистичних характеристик фрактальної розмірності (ФР) акустичних сигналів безпілотних літальних апаратів (БпЛА), широкосмугового шуму та шуму вітру. Встановлено, щзо значення ФР для широкосмугового шуму підпорядковані нормальному законові розподілу щільності ймовірностей. Запропоновано алгоритм виявлення акустичних сигналів БпЛА на основі аналізу ФР з постійною ймовірністю хибної тривоги. Особливістю алгоритму є те, щзо значення порогу не залежить від потужності широкосмугового шуму. Проведено дослідження робочих характеристик запропонованого алгоритму. Встановлено залежність ймовірності правильного виявлення акустичного сигналу БпЛА при заданих значеннях ймовірності хибної тривоги від довжини вікна аналізу сигналу та мінімальної кількості інтервалів розбиття даного вікна при розрахунку ФР із використанням показника Херста. Вказано умови для досягнення оптимальних значень показників якості виявлення.

Ключові слова: безпілотний літальний апарат, акустичний сигнал, показник Херста, фрактальна розмірність, алгоритм виявлення.

\section{Вступ}

Постановка проблеми. У зв'язку 3 розширенням сфери застосування малорозмірних БПЛА та збільшенням кількості загроз, які вони можуть створювати, завдання своєчасного та достовірного виявлення таких літальних апаратів $€$ важливим та актуальним [1 2]. Складність виявлення таких БпЛА зумовлена їх низькою помітністю в радіолокаційному, інфрачервоному та оптичному діапазонах довжин хвиль. У зв'язку 3 цим в останні роки зросла зацікавленість до виявлення таких БпЛА із використанням пасивних акустичних систем [3 9]. Особливостями акустичних сигналів БпЛА, що ускладнюють їх виявлення, $\epsilon$ відносно малий рівень звукової потужності та широка смуга частот (порівняно 3 іншими акустичними сигналами), а також висока апріорна невизначеність відносно структури як акустичних сигналів БпЛА, так i перешкод $\left[\begin{array}{ll}10 & 11\end{array}\right]$.

Дослідження складних коливань, до яких відносяться і акустичні сигнали БпЛА, шляхом аналізу відповідних фазових портретів та ФР дає більше інформації, ніж спостереження часових реалізацій і спектрів [12]. Тому розроблення та дослідження алгоритмів виявлення акустичних сигналів БпЛА на основі аналізу ФР є актуальним завданням, вирішення якого дозволить проводити надійне виявлення БпЛА пасивними акустичними системами.

Аналіз останніх досліджень і публікацій. Дослідженню особливостей акустичних сигналів БпЛА та підходів до їх аналізу та виявлення присвячена значна кількість публікацій вітчизняних та закордонних авторів [3 111$]$. Основну увагу при вирішенні завдання виявлення акустичних сигналів БпЛА дослідники зосереджують на використанні методів частотного $[4,6,7]$, частотно-часового $[5,13,14]$ та кореляційного аналізу [8].

Також останнім часом для виявлення та розпізнавання відбитих від лопатей БпЛА мультироторного типу радіолокаційних сигналів використовують величини ФР фазових портретів [15 16].

Невирішеними залишаються питання дослідження ФР акустичних сигналів БпЛА та оцінювання можливості ऑіi використання для виявлення БпЛА.

Метою статті $є$ розроблення та дослідження алгоритму виявлення акустичних сигналів БпЛА на основі аналізу їх фрактальної розмірності.

\section{Методи дослідження}

При проведенні досліджень було використано математичний апарат теорії ймовірностей i математичної статистики, методи математичного моделювання.

Виклад основного матеріалу дослідження

\section{Дослідження фрактальної розмірності акустичних сигналів БпЛА}

Зацікавленість фрактальним аналізом зумовлена тим, що такий вид обробки дозволяє оцінити інтегральні характеристики сигналів, які не залежать від моменту приходу і розраховуються для всієї довжини сигналу. 
Для більшості часових рядів аналітичне знаходження ФP D $€$ неможливим, тому iii визначають чисельно, найчастіше через величини, пов'язані з нею простим співвідношенням. Одним iз основних методів визначення ФР числових рядів на сьогоднішній день $є$ обчислення показника Херста. Даний спосіб дослідження фрактальних часових рядів ( $\mathrm{RS}$-метод) грунтується на аналізі відношення розмаху параметра $\mathrm{R}$ (різниці між його найбільшим i найменшим значеннями на відрізку) до його середньоквадратичного відхилення (СКВ) S показника Херста Н, який широко застосовують завдяки своїй стійкості. Даний показник містить мінімальні припущення про сигнал і може класифікувати часові ряди, відрізняючи випадковий ряд від невипадкового, навіть якщо значення відліків випадкового ряду розподілені не за нормальним законом [17]. Для гаусових сигналів показник Херста пов'язаний 3 ФP D співвідношенням $\mathrm{D}=2-\mathrm{H}$. Для отримання надійної чисельної оцінки ФР необхідною є значна кількість даних (порядку $10^{3} 10^{4}$ значень), тому отримані результати дають уяву лише про загальні властивості ряду на великих масштабах, всередині яких часовий ряд може кілька разів змінити характер своєї поведінки. ФР, як правило, є додатнім нецілим числом і відображає складність

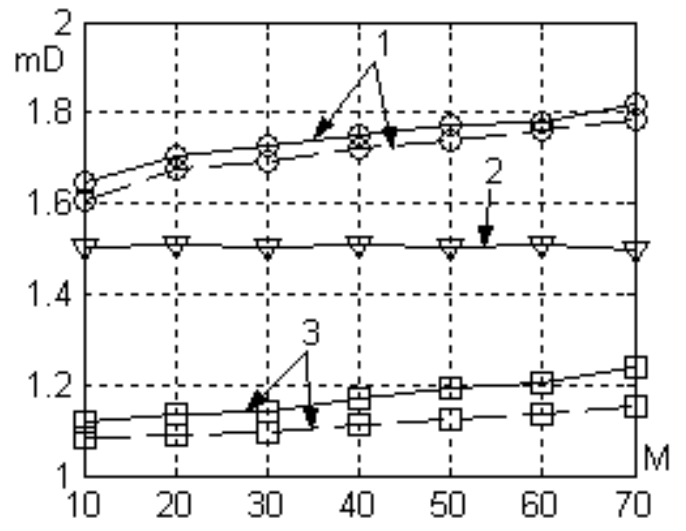

a)

Рис. 1. Залежність вибіркових середнього mD (а) та СКB SD (б) ФР D від мінімальної кількості елементів розбиття $M: 1$ - сигнал БпЛА; 2 - широкосмуговий шум; 3 - шум вітру

Із наведених залежностей видно, що при збільшенні довжини вікна $\mathrm{N}$ i $\mathrm{M}=\mathrm{const}$ для широкосмугового шуму вибіркове середнє ФР залишається незмінним, а СКВ зменшується. При цьому для сигналу БпЛА і шуму вітру вибіркове середнє зростає, а СКВ зменшується.

При збільшенні M i $\mathrm{N}=$ const для сигналу БПЛА і вітру середнє вибіркове зростає, а для шуму залишається практично незмінним. При цьому для широкосмугового шуму і шуму вітру вибіркове СКВ збільшується, а для сигналу БпЛА зменшується.

Виходячи 3 аналізу наведених залежностей можна зробити висновок, що множина значень ФР широкосмугового шуму знаходиться ближче відповідної множини сигналу БпЛА, ніж множина значень ФР шуму вітру. Тому очевидно, що при форми сигналу. При двомірному представленні прийнятого сигналу, величина ФР знаходиться в межах $1 \leq \mathrm{D} \leq 2[18]$.

В даній роботі для визначення ФР було використано показник Херста. Розрахунок ФР акустичного сигналу БпЛА 3 двигуном внутрішнього згорання і повітряним гвинтом, широкосмугового шуму 3 рівномірною спектральною щільністю потужності та шуму вітру було проведено для записів відповідних сигналів при розрядності аналого-цифрового перетворювача 16 біт і частоті дискретизації 8 кГц. Довжина реалізацій кожного із записів становила близько $3 \times 10^{5}$ відліків. Обчислення ФР проводилося у сусідніх вікнах без перекриття довжиною $10^{3}$ і $2 \times 10^{3}$ відліків. Графіки залежностей вибіркових середнього $\mathrm{mD}$ та $\mathrm{CKB} \mathrm{sD}$ ФР від мінімальної кількості елементів розбиття вікна сигналу $\mathrm{M}$ наведено на рис. 1 (а) та (б) відповідно. Суцільною лінією показано криві для довжини вікна $\mathrm{N}=2000$ відліків, а пунктирною для $\mathrm{N}=1000$. Фоновий широкосмуговий шум iз рівномірною щільністю спектральної потужності та шум вітру було обрано як типові сигнали на фоні яких проводиться виявлення акустичного сигналу БпЛА.

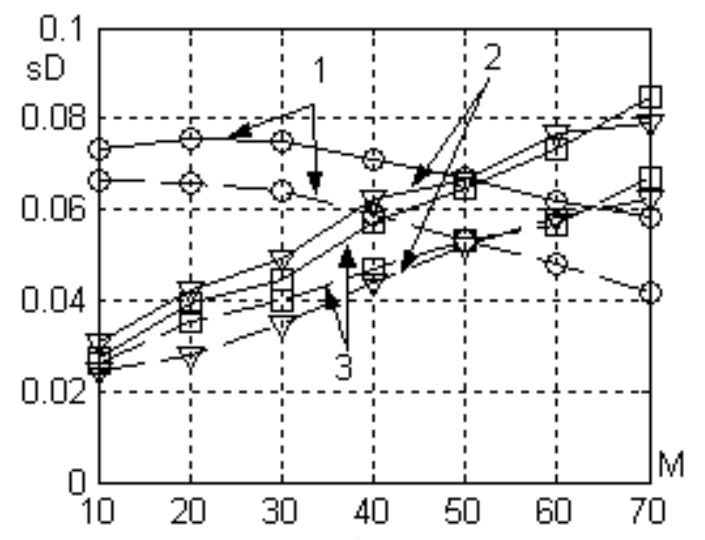

б) спостереженні акустичного сигналу БпЛА на фоні вітру ймовірність його правильного виявлення $\mathrm{P}_{\mathrm{D}}$ буде вищою, ніж при спостереженні на фоні широкосмугового шуму.

\section{Розроблення алгоритму виявлення} акустичного сигналу БпЛА

При виявленні сигналів однією 3 ключових задач є задача знаходження порогу [19]. Оскільки для різних типів БпЛА значення ФР можуть відрізнятися, а для широкосмугового шуму дані значення є стійкими, тому значення порогу будемо обирати для фіксованого значення ймовірності хибної тривоги $\mathrm{P}_{\mathrm{F}}$.

Виходячи 3 аналізу алгоритму розрахунку показника Херста [20] та на основі центральної граничної теореми можна припустити, що розподіл значень ФР для широкосмугового шуму є 
нормальним. Тоді значення порогу для заданого значення ймовірності хибної тривоги $\mathrm{P}_{\mathrm{F}}$ можна знайти як правосторонній квантиль нормальної кривої розподілу щільності ймовірностей при знайдених значеннях вибіркових середнього та СКВ для заданих $\mathrm{N}$ і M .

В табл. 1 наведено теоретичні значення порогів

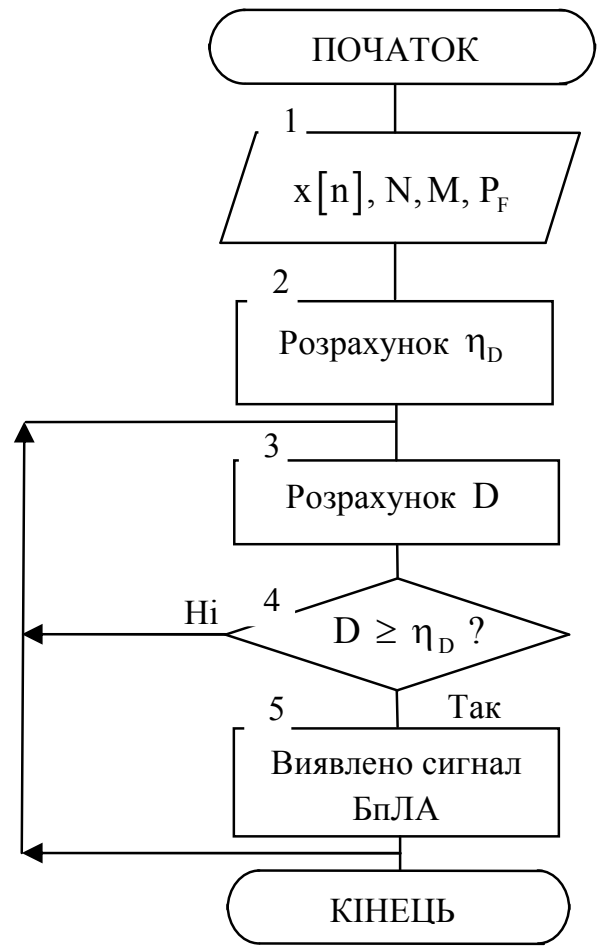

Рис. 2. Алгоритм виявлення акустичного сигналу БпЛА

для різних ймовірностей хибної тривоги $\mathrm{P}_{\mathrm{F}}$ при $\mathrm{M}=30$ та $\mathrm{M}=70$.
У результаті проведеного математичного моделювання за допомогою методу Монте-Карло було встановлено, що розраховані значення порогів забезпечують значення ймовірності хибної тривоги не вище наведених у табл. 1.

Запропонований алгоритм виявлення акустичного сигналу БпЛА наведено на рис. 2. Вхідними даними алгоритму є відліки акустичного сигналу $\mathrm{x}[\mathrm{n}]$, довжина вікна $\mathrm{N}$, мінімальна кількість інтервалів розбиття вікна $\mathrm{M}$ та ймовірність хибної тривоги $\mathrm{P}_{\mathrm{F}}$. Після розрахунку значення порогу $\eta_{\mathrm{D}}$ визначають значення ФР D відліків прийнятої реалізації та порівнюють розраховане значення 3 порогом. У разі перевищення порогу приймається рішення про виявлення акустичного сигналу БпЛА.

\section{Дослідження показників якості розробленого алгоритму}

Методом статистичного моделювання в середовищі MATLAB було розраховано залежності значень статистичної ймовірності правильного виявлення $\mathrm{P}_{\mathrm{D}}$ акустичного сигналу БпЛА на фоні широкосмугового шуму від відношення сигнал-шум (ВСШ) q . Значення ВСШ змінювалося в діапазоні від -14 дБ до 34 дБ 3 кроком 2 дБ.

На рис. 3 (а) наведено робочі характеристики розробленого алгоритму у вигляді кривих виявлення для значень ймовірності хибної тривоги в діапазоні від $10^{-1}$ до $10^{-6}$ для довжини вікна аналізу 1000 відліків. Аналогічні криві виявлення для довжини вікна аналізу 2000 відліків наведено на рис. 3 (б). Мінімальна кількість інтервалів розбиття вікна М сигналу для обох випадків складає 30.

Таблиия 1

Значення порогів для заданої ймовірності хибної тривоги

\begin{tabular}{|c|c|c|c|c|c|c|c|c|c|c|}
\hline \multirow{2}{*}{$P_{F}$} & \multicolumn{9}{|c|}{$\mathrm{M}=30$} & \multicolumn{5}{c|}{$\mathrm{M}=70$} \\
\cline { 2 - 11 } & $10^{-1}$ & $10^{-2}$ & $10^{-3}$ & $10^{-4}$ & $10^{-5}$ & $10^{-1}$ & $10^{-2}$ & $10^{-3}$ & $10^{-4}$ & $10^{-5}$ \\
\hline $\mathrm{N}=10^{3}$ & 1,56 & 1,62 & 1,64 & 1,69 & 1,71 & 1,61 & 1,69 & 1,76 & 1,81 & 1,86 \\
\hline $\mathrm{N}=2 \cdot 10^{3}$ & 1,55 & 1,57 & 1,62 & 1,64 & 1,65 & 1,58 & 1,64 & 1,68 & 1,72 & 1,75 \\
\hline
\end{tabular}

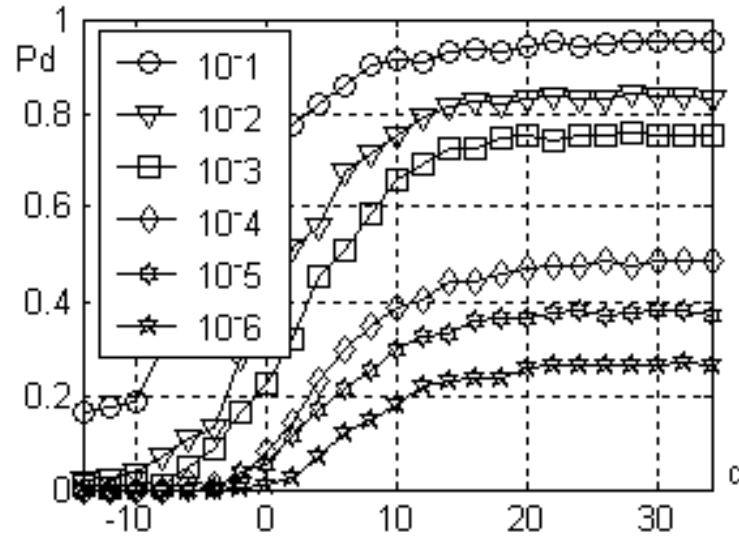

a)

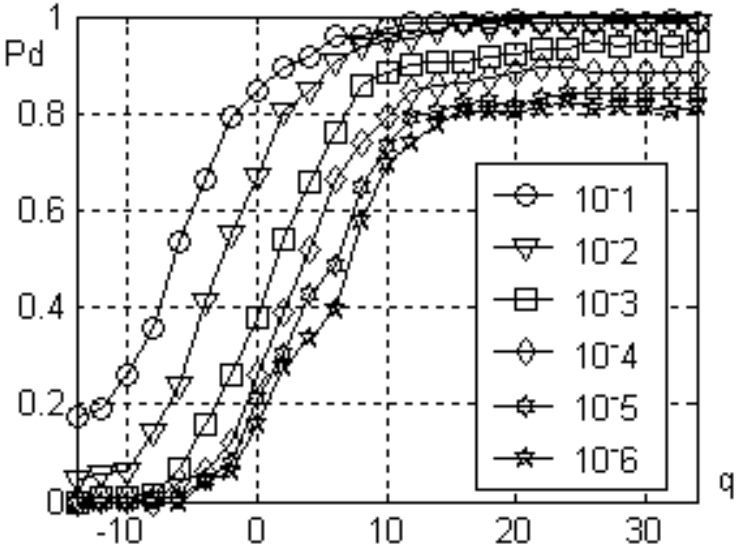

б)

Рис. 3. Криві виявлення акустичного сигналу БПЛА для $\mathrm{M}=30$ i $\mathrm{N}=1000$ (a) та $\mathrm{N}=2000$ (б) 
На рис. 4 (a, б) наведено аналогічні криві виявлення розробленого алгоритму для

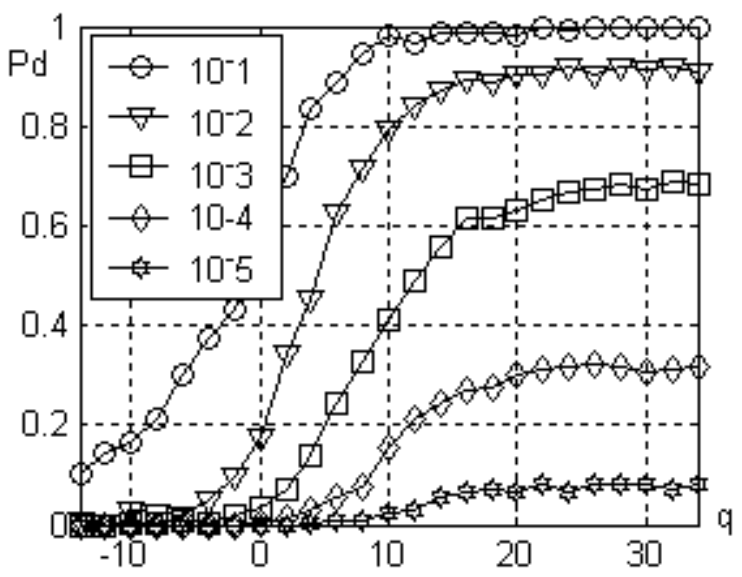

a) мінімальної кількості інтервалів розбиття вікна сигналу $\mathrm{M}=70$.

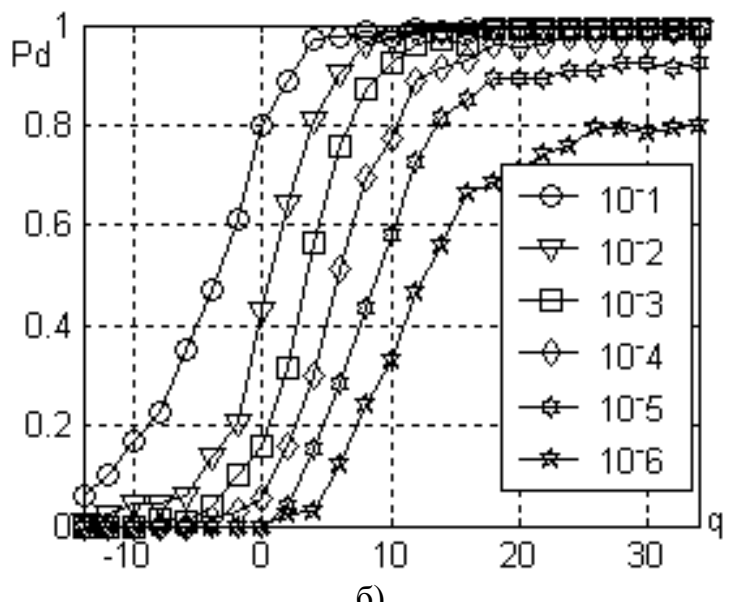

Рис. 4. Криві виявлення акустичного сигналу БпЛА для $\mathrm{M}=70$ i $\mathrm{N}=1000$ (a) та $\mathrm{N}=2000$ (б)

Особливістю отриманих кривих виявлення є те, що для деяких значень М i $\mathrm{N}$ при збільшенні ВСШ значення ймовірності правильного виявлення прямує не до 1, а до деякого меншого значення. Це пояснюється тим, що значення ФР, а отже і порогу, не залежить від потужності шуму, а визначається його структурними особливостями.

Аналіз наведених кривих виявлення дає змогу зробити висновок, що при $\mathrm{M}=$ const i збільшенні $\mathrm{N}$ криві виявлення для однакових значень $\mathrm{P}_{\mathrm{F}}$ будуть зсунутими вліво і рівень, до якого вони наближатимуться при зростанні ВСШ також буде збільшуватися. При $\mathrm{N}=$ const i збільшенні $\mathrm{M}$ криві виявлення для однакових значень ймовірності хибної тривоги будуть зсунутими вправо.

Як бачимо, підвищення ймовірності правильного виявлення можна досягти за рахунок збільшення довжини вікна $\mathrm{N}$, або зменшення мінімальної кількості інтервалів розбиття вікна сигналу М. Проте при зменшенні М вибіркове середнє ФР акустичного сигналу БпЛА наближається до аналогічної величини широкосмугового шуму i, крім того, збільшується СКВ ФР акустичного сигналу БпЛА. Тому для конкретного акустичного сигналу БпЛА існує таке оптимальне мінімальне значення кількості інтервалів розбиття сигналу $\mathrm{M}_{\text {opt }}$, що при заданих значеннях $\mathrm{N}, \mathrm{P}_{\mathrm{F}} \mathrm{i}$ q забезпечує найвище значення ймовірності правильного виявлення. В даному випадку методом перебору було встановлено, що $\mathrm{M}_{\mathrm{opt}} \approx 30$.

Таким чином, для підвищення ймовірності

\section{Jimepamypa}

1. Артюшин Л. М. Аерокосмічна розвідка в локальних війнах сучасності: досвід проблемні питання і тенденції. Монографія. Київ : НАОУ, 2002. 208 с. 2. CounterUnmanned Aircraft System Techniques : Techniques Publication ATP 3-01.81. Headquarters Department of the Army Washington, DC, 2017.48 p. 3. Minas B., Goldman G. H. Acoustic detection and tracking of a class I правильного виявлення акустичного сигналу БПЛА на фоні широкосмугового шуму при заданих ймовірності хибної тривоги і ВСШ необхідно збільшувати довжину вікна аналізу сигналу при оптимальній мінімальній кількості інтервалів його розбиття при обчисленні показника Херста.

\section{Висновки}

Відмінність у значеннях фрактальних розмірностей акустичного сигналу БпЛА, широкосмугового шуму та шуму вітру може бути використана при розробленні алгоритмів виявлення акустичних сигналів БпЛА. Значення ймовірності хибної тривоги при фіксованому значенні порогу не залежить від потужності широкосмугового шуму. Підвищити ймовірність правильного виявлення акустичного сигналу БпЛА на фоні широкосмугового шуму при заданих ймовірності хибної тривоги і відношенні сигналшум можливо за рахунок збільшення довжини вікна аналізу сигналу. Запропонований алгоритм може бути використаний у пасивних акустичних системах виявлення БпЛА.

До переваг запропонованого алгоритму можна віднести простоту реалізації та інваріантість значення порогу до потужності широкосмугового шуму. Недоліком підходу $є$ те, що роботу алгоритму в оптимальному режимі можна забезпечити лише для відомого акустичного сигналу БпЛА.

Перспективи подальших досліджень у даному напрямку пов'язані 3 удосконаленням розробленого алгоритму для виявлення акустичних сигналів БпЛА на фоні інших акустичних сигналів.

UAS with a small tetrahedral microphone array. Adelphi, MD 20783-1138, ARL-TR-7086 Report, 2014. 34 p. 4. Бугайов М. В. Алгоритм виявлення акустичних сигналів безпілотних літальних апаратів // Вісник ЖДТУ. Серія: Технічні науки. Житомир : ЖДТУ, 2015. № 74 (3). C. 46-53. 5. Bougaiov N., Danik Yu. Hough transform for UAV's acoustic signals detection // The 
Advanced Science Journual. Scripers Corporation, United States. Volume 2015 ISSUE 6. P. 65-68. 6. Harvey B., O'Young S. Acoustic Detection of a Fixed-Wing UAV // MDPI Drones, 2018. 18 p. 7. Bernardini A., Mangiatordi F., Pallotti E. et al. Drone detection by acoustic signature identi cation // IS\&T International Symposium on Electronic Imaging, 2017. P. 60 64. 8. Hauzenberger L., Ohlsson E. H. Drone Detection using Audio Analysis // Master's Thesis Department of Electrical and Information Technology, Faculty of Engineering, LTH, Lund University, 2015. 66 р. 9. Зінченко С. А., Свіжевський В. Ф. Пасивна акустична система виявлення безпілотних літальних апаратів // Інформаційна безпека України : наук.-техн. конф., 12-13 березня 2015 р.: тези доп. Київ : КНУ, 2015. С. 74-75. 10. Гордіснко Ю. О., Бугайов М. В., Солонець I. О. та ін. Особливості акустичних сигналів безпілотних літальних апаратів // Наука і техніка Повітряних Сил Збройних Сил України. Харків : ХУПС, 2016. № 1(22). - С. 32-35. 11. Kloet N., Watkins S., Clothier R. Acoustic signature measurement of small multi-rotor unmanned aircraft systems // International Journal of Micro Air Vehicles. RMIT University, Melbourne, Australia, 2017. Vol.9(1). P. 314. 12. Анищенко В. С. Сложные колебания в простых системах: Механизмы возникновения, структура и свойства динамического хаоса в радиофизических системах. Москва : Наука. Гл. ред. физ.-мат. лит., 1990. 312 c. 13. Ferguson B. G., Quinn B. G. Application of the short-time Fourier transform and the Wigner-Ville distribution to the acoustic localization of aircraft // J.
Acoust. Soc. Am, 1994. Vol. 96, № 2. P. 821-827. 14. Даник Ю. Г., Бугайов М. В. Частотно-часовий аналіз акустичного випромінювання тактичних безпілотних літальних апаратів // Проблеми створення, випробування, застосування та експлуатації складних інформаційних систем : зб. наук. праць. Житомир : ЖВІ, 2015. Вип. 12. С. 5-17. 15. Пащенко Р. Э., Кортунов В. И., Цюпак Д. О. и др. Распознавание БПЛА мультироторного типа с использованием фазовых портретов // Наука і техніка Повітряних Сил Збройних Сил України. Харків : ХУПС 2013. № 4(13). С. 6872. 16. Пащенко Р. Э., Фатеев А. С., Цюпак Д. О. и др. Анализ величин фрактальных размерностей фазовых портретов для распознавания БПЛА мультироторного типа // Наука і техніка Повітряних Сил Збройних Сил України. Харків : ХУПС 2016. № 1(22). С. 8387. 17. Степанов Д. В., Кузовников А. В., Степанов Д. В. Исследование фрактальных свойств радиосигналов // Вестник Сибирского государственного аэрокосмического университета имени академика М. Ф. Решетнева. Новосибирск: ГАУ, 2010. С. 3539. 18. Федер Е. Фракталы. пер. с англ. Ю. А. Данилова. Москва : Мир, 1991261 с. 19. Акимов П. С., Бакут П. А., Богданович В. А. и др. Теория обнаружения сигналов. Москва : Радио и связь, 1984.440 с. 20. Чумак О. В. Энтропии и фракталы в анализе данных. Москва : Ижевск: НИЦ «Регулярная и хаотическая динамика», Институт компьютерных исследований, 2011. 164 с.

\title{
АЛГОРИТМ ОБНАРУЖЕНИЯ АКУСТИЧЕСКИХ СИГНАЛОВ БЕСПИЛОТНЫХ ЛЕТАТЕЛЬНЫХ АППАРАТОВ НА ОСНОВЕ АНАЛИЗА ФРАКТАЛЬНОЙ РАЗМЕРНОСТИ
}

\author{
Леонид Михайлович Артюшин (доктор техн. наук, профессор) ${ }^{1}$ \\ Николай Викторович Бугаёв (канд. техн. наук, научный сотрудник)
}

\section{${ }^{1}$ Государственный научно-исследовательский институт авиации, Киев, Украина ${ }^{2}$ Житомирский военный институт имени С. П. Королёва, Житомир, Украина}

В работе проведен анализ статистических характеристик фрактальной размерности (ФР) акустических сигналов беспилотных летательных аппаратов (БпЛА), широкополосного шума и шума ветра. Установлено, что значение ФР для широкополосного шума подчинены нормальному закону распределения плотности вероятностей. Предложен алгоритм обнаружения акустических сигналов БпЛА на основе анализа ФР с постоянной вероятностью ложной тревоги. Особенностью алгоритма является то, что значение порога не зависит от мощности широкополосного шума. Проведено исследование рабочих характеристик предложенного алгоритма. Установлена зависимость вероятности правильного обнаружения акустического сигнала БпЛА при заданных значениях вероятности ложной тревоги от длинь окна анализа сигнала и минимального количества интервалов разбиения данного окна при расчете ФР с использованием показателя Херста. Указаны условия для достижения оптимальных значений показателей качества обнаружения.

Ключевые слова: беспилотный летательный аппарат, акустический сигнал, показатель Херста, фрактальная размерность, алгоритм обнаружения.

\section{ALGORITHM OF UNMANNED AERIAL VEHICLES ACOUSTIC SIGNALS DETECTION BASED ON ANALYSIS OF FRACTAL DIMENSION}

\author{
Leonid M. Artushin (Doctor of Technical Science, Professor) \\ Mykola V. Buhaiov (Candidate of Technical Sciences, Researcher) ${ }^{2}$ \\ ${ }^{1}$ State research institute of aviation, Kyiv, Ukraine \\ ${ }^{2}$ Zhytomyr military institute named after $S$. P. Korolov, Zhytomyr, Ukraine
}

In this paper the statistical characteristics of the fractal dimension (FD) of acoustic signals of unmanned aerial vehicles (UAV), broadband noise and wind noise are analyzed. It is established that the values of FD for broadband noise are subordinated to the normal probability density distribution law. An algorithm for detecting of UAV acoustic signals based on the analysis of FD with a constant probability of false alarm is proposed. The 
feature of the algorithm is that the threshold value does not depend on the power of the broadband noise. The research of the operational characteristics of the proposed algorithm is carried out. The dependence of the probability of detection of UAV's acoustic signal with given values of the probability of false alarm, length of the window of the signal analysis and the minimum number of intervals of the partition of the given window when calculating the FD using the Hurst index is established. Specified conditions for achieving the optimal values of the probability of detection. It is shown that increasing the probability of UAV's acoustic signal detecting at the background of broadband noise at given probabilities of false alarm and the signal to noise ratio is possible by increasing the length of the window of the signal analysis. The proposed algorithm can be used in passive acoustic detection systems. algorithm.

Key words: unmanned aerial vehicle, acoustic signal, Hurst index, fractal dimension, detection

\section{References}

1. Artiushyn L. M., Mosov S. P., Piaskovkij D. V., Tolubko B. V. (2002), Aerospace intelligence in local wars of the present: experience, issues and trends. Monograph. [Aerokosmichna rozvidka $v$ lokal'nykh viynakh suchasnosti: dosvid, problemni pytannya $i$ tendentsiyi. Monohrafiya], NDUU, Kiev, 208 p. 2. Counter-Unmanned Aircraft System Techniques : Techniques Publication ATP 3-01.81. Headquarters Department of the Army Washington, DC, 2017, 48 p. 3. Minas B., Goldman G. H. (2014), Acoustic detection and tracking of a class I UAS with a small tetrahedral microphone array, Adelphi, MD 20783-1138, ARL-TR-7086 Report, 34 p. 4. Buhaiov M. V. (2015), Algorithm of unmanned aerial vehicles acoustic signals detecting. [Alhorytm vyyavlennya akustychnykh syhnaliv bezpilotnykh lital'nykh aparativ], Visnuk ZDTU, № 74 (3), pp. 46-53. 5. Bougaiov N., Danik Yu. (2015), Hough transform for UAV's acoustic signals detection, The Advanced Science Journual. Scripers Corporation, United States. Volume ISSUE 6, pp. 65-68. 6. Harvey B., O'Young S. (2018), Acoustic Detection of a Fixed-Wing UAV, MDPI Drones, 18 p. 7. Bernardini A., Mangiatordi F., Pallotti E., Capodiferro L. et al. (2017), Drone detection by acoustic signature identi cation, IS\&T International Symposium on Electronic Imaging, P. 6064. 8. Hauzenberger L., Ohlsson E. H. (2015), Drone Detection using Audio Analysis, Master's Thesis Department of Electrical and Information Technology, Faculty of Engineering, LTH, Lund University, $66 \mathrm{p}$. 9. Zinchenko S. A., Svijevskij V. P. (2015), Passive acoustic system for unmanned aerial vehicles detection. [Pasyvna akustychna systema vyyavlennya bezpilotnykh lital'nykh aparativ], tezy dopovidey naukovo-tekhnichnoi konferentsii Informatsiyna bezpeka Ukrayiny, pp. 74-75. 10. Gordienko Y. O., Buhaiov M. V., Solonets O. I., Solopij I. A. (2016), Features of acoustic signals of unmanned aerial vehicles. [Osoblyvosti akustychnykh syhnaliv bezpilotnykh lital'nykh aparativ], Nauka i tekhnika Povitryanykh Syl Zbroynykh Syl Ukrayiny, No 1 (22), pp. 32-35. 11. Kloet N., Watkins S., Clothier R. (2017), Acoustic signature measurement of small multi-rotor unmanned aircraft systems, International Journal of Micro Air Vehicles., RMIT University, Melbourne, Australia,
Vol. 9 (1)., P. 3 14. 12. Anishchenko V.S. (1990), complex oscillations in simple systems: mechanisms of formation, structure and properties of dynamic chaos in radiophysical systems. [Slozhnyye kolebaniya $v$ prostykh sistemakh: Mekhanizmy vozniknoveniya, struktura i svoystva dinamicheskogo khaosa $v$ radiofizicheskikh sistemakh], Nauka, Moskow, 312 p. 13. Ferguson B. G., Quinn B. G. (1994), Application of the short-time Fourier transform and the Wigner-Ville distribution to the acoustic localization of aircraft, J. Acoust. Soc. Am, Vol. 96, № 2., P. 821-827. 14. Danyk Y. G., Buhaiov M. V. (2015), Time-frequencytime analysis of tactical unmanned aerial vehicles acoustic signals. [Chastotno-chasovyy analiz akustychnoho vyprominyuvannya taktychnykh bezpilotnykh lital'nykh aparativ], Problemy stvorennya, vyprobuvannya, zastosuvannya ta ekspluatatsiyi skladnykh informatsiynykh system, No 12, pp. 5-17. 15. Pashchenko R. E., Kortunov V. I., Tsiupak D. O., Bardanova O. A. (2013), Recognition of multi-rotor UAV using phase portraits. [Raspoznavaniye BPLA mul'tirotornogo tipa $s$ ispol'zovaniyem fazovykh portretov], Nauka i tekhnika Povitryanykh Syl Zbroynykh Syl Ukrayiny, No 4 (13), pp. 68 72. 16. Pashchenko R. E., Fatieiev A. S,. Tsiupak D. O., Romantsov A. A. (2016), Analysis of fractal dimensions of phase portraits for recognition of multi-rotary UAV. [Analiz velichin fraktal'nykh razmernostey fazovykh portretov dlya raspoznavaniya BPLA mul'tirotornogo tipa], Nauka i tekhnika Povitryanykh Syl Zbroynykh Syl Ukrayiny, No 1 (22), pp. 83 87. 17. Stepanov D. V., Kyzovnikov A. V., (2010), Investigation of fractal properties of radio signals. [Issledovaniye fraktal'nykh svoystv radiosignalov], Vestnik Sibirskogo gosudarstvennogo aerokosmicheskogo universiteta imeni akademika M. F. Reshetneva, pp. 35 39. 18. Feder E. (1991), Fractals. [Fraktaly], Mir, Moskow, 261 p. 19. Akimov P. S., Bakut P. A., Bogdanovich V. A. (1984), Signal detection theory. [Teoriya obnaruzheniya signalov], Radio i svyaz', Moskow, 440 p. 20. Chumak O. V. (2011), Entropies and fractals in data analysis. [Entropii i fraktaly $v$ analize dannykh], Regulyarnaya i khaoticheskaya dinamika, Moskow, $164 \mathrm{p}$. 